\title{
En torno a una obra sobre integración latinoamericana*
}

Entre 1965 y 1975 circularon en América Latina múltiples obras, monografías, artículos y comentarios sobre el tema de la integración regional, vista, preferentemente, desde enfoques políticos, económicos o jurídicos.

Cuantitativamente, por cierto, el número de estudios no guardaba relación directa, ni con la importancia política atribuida al tema por los gobiernos, ni con el contenido y alcance jurídico o económico de los instrumentos que "trataban" de ponerse en aplicación para desarrollar el proceso. Con todo, a pesar de lo "desmesurada" que hoy nos parece la inquietud de los analistas y académicos de la región; ella, en términos generales, fue positiva, tanto tratándose de ALALC como del Grupo Andino.

Recordemos que las tendencias más perceptibles de esos estudios, respondían a dos enfoques diferentes del problema. O bien, se aceptaba por el análisis "genérico" del proceso; como si éste obedeciese, en todas partes y en todo momento, a unas leyes universales, con instrumentos comunes (los que no eran objeto de un mayor análisis) y donde, artificiosamente, se proyectaba la "región" (o la subregión, en su caso) como un "bloque" más o menos estructurado, con todas las indiscutibles ventajas del caso; o bien, se recurría al comentario circunscrito a los instrumentos aprobados, como si ellos fueran inmutables y plenamente conducentes a la obtención de los propósitos perseguidos.

La verdad es que era difícil encontrar análisis donde se tratara de ubicar la política de integración regional en el contexto real de la política exterior de cada país. Más difícil aún era encontrar análisis de las actitudes específicas adoptadas por los países (gobiernos y empresarios) frente a cada uno de los principales instrumentos elegidos, los que perfilaban, por lo demás, la exacta naturaleza deI proceso, cuyos contornos se prefería mantener indefinidos. Con

*Manfred Wilhelmy (editor), Sociedad, Politica e Integración en América Latina. Ediciones CINDE, febrero de 1982. 
todo, se le atribuía al proceso presunciones de ser conocido, necesario, e, incluso "irreversible".

Cuando se optaba, en cambio, por analizar un instrumento concreto del esquema, fuese la liberación comercial, la complementación sectorial, o el régimen común al capital extranjero, por ejemplo, aparté de hacerse una apología o una crítica del mismo, los autores no se preocupaban de continuar con el "seguimiento" del tema. Podía suceder que el instrumento se agotara, no se cumpliera o fuera desechado, pero la inquietud publicitaria inicial no era continuada. Con ello, implícitamente, se daba por hecho su perfecciónamiento cabal a raíz del acto de su aprobación, o su absoluta inutilidad posterior, la cual no merecía el menor comentario.

Los críticos "instrumentales", tampoco se daban el trabajo de verificar la magnitud de sus pronósticos, entonces disidentes y minoritarios.

Ya en 1975, se estimó, al parecer por consenso digno de mejor causa, que el proceso se había "saturado" y así, a la euforia inicial, no siguió un progresivo desvanecimiento de la inquietud, sino una especie de conspiración no deliberada del silencio. No deliberada, pero bastante radical.

La puesta en vigencia, en octubre de 1975, del Convenio de Panamá que creó el sELA y el comentario en torno a algunas manifestaciones políticas externas del Grupo Andino, quebraron fragmentariamente, la conspiración no deliberada del silencio. Pero nạda más. Ni siquiera el Tratado de Montevideo 1980, que creó la Asociación Latinoamericana de Integración, escapó a la regla. Salyo el caso de revistas especializadas exclusivamente en el tema y en Ta producción de los habituales informes y estudios de los organismos regionales pertinentes, la integración regional era retirada de la agenda de preocupaciones de los intelectuales latinoamericanòs. Lo más curioso es que al lado de los nuevos temas de relevo, la solidaridad regional debería haber merecido un capítulo recurrente, por cuanto no es contradictoria, ni irrelevante, ni ajena a ellos. Me refiero a las relaciones económicas "Norte-Sur"; "Sur-Sur"; "EsteOeste" y al estudio de la transnacionalización financiera, económica, cultural e informativa, o al de la recesión económica generalizada.

La necesidad de la integración regional tiene nuevos y valiosos argumentos. La readecuación de los instrumentos de integración y cooperación ofrece una vasta posibilidad de investigaciones y estudios. Si el propio mercado regional no resulta solidario para nuestros países, resulta para muchos incomprensible golpear puertas ajenas. El panorama de solidaridades regionales después de los sucesos de Las Malvinas, por lo demás, parece "alterado". Esos son temas primordiales de investigación. 
Dentro de ese orden de ideas, los estudios realizados por la Corporación de Investigaciones para el Desarrollo, arNDE, sobre el tema de la Sociedad, Politica e Integración en América Latina, son doblemente excepcionales. Primero, por el hecho puro y simple de su aparición (agosto 1981) y, segundo, por su contenido.

No es nuestra intención hacer un análisis de la obra en su integridad; tarea que emprende uno de sus autores: Manfred Wilhelmy en el capítulo final de la misma, sino que comentar algunas afirmaciones contenidas en ella, sugeridas por la experiencia y la observación personal de los hechos allí descritos; centrándonos exclusivamente en la variable "integración" expuesta por los autores. Luciano Tomassini, en el Gapítulo. 5 de la publicación ("La integración y el cambio de las estrategias de desarrollo") después de describir las nuevas circunstancias políticas y económicas del área (en forma breve, pero suficiente para el propósito que persigue) señala "Ios nuevos objetivos" que un proceso de integración y cooperación debería perseguir en los consiguientes "replanteamientos" del caso.

Está claro que si no existe acuerdo en los objetivos básicos del proceso, no podrá haber una comunidad regional orientada en un sentido determinado. Lamentablemente, este grave vacío conceptual previo se dio a raíz de la aprobación del Tratado de Montevideo 1960 que creara ALALC, y son varios los analistas de la misma que estiman que dicho esquema cumplió su objetivo injicial; cual era el de crear un espacio comercial preferencial negociado anualmente, producto por producto, que permitiera elevar el intercambio comercial recíproco a los más altos niveles posibles, en esfuerzos multilaterales. La mayoría, en cambio, pensaba que alala respondía a la necesidad de crear las condiciones propias de un mercado común regional al estilo del de Europa Occidental, que fuera promoviendo un desarrollo integrado en el área con los máximos elementos posibles de coordinación de políticas económicas. Al no definirse el Tratado por objetivos precisos, las dos interpretaciones exan posibles pero, obviamente, los criterios y las esperanzas propias de cada una de ellas tenían que ser irreductiblemente diferentes.

El Acuerdo de Cartagena de mayo de 1969 reaccionó frente a esa ambigüedad teleológica, definiendo muy claramente sus objetivos. Otra cuestión, es la de ver si los instrumentos y mecanismos estructurados fueron Ios adecuados.

Para el autor comentado, los objetivos de la integración y cooperación regional, serían "algunos de Ios siguientes":

- Contribuir al incremento de la capacidad de defensa de los países de la región mediante estrategias selectivas de "crecimiento hacia dentro a nivel regional" y una "revalorización del mercado latinoamericano"; 
- Ayudar al ejercicio de una mayor capacitación regional en materias como el "control y el procesamiento local de sus recursos naturales", "una mayor capacidad para manejax y adaptar los flujos de tecnología externa" y "el logro de un mayor margen de seguridad financiera";

- "Efectuar una contribución al aumento de la eficiencia y la competitividad de ciertas actividades industriales frente al resto entre los países de la región en algunos sectores específicos";

- "Facilitar la coordinación de las políticas económicas externas de los países de la región en un mundo cada vez más interdependiente";

- "Contribuir, a través de una acción concertada, a incrementar la gravitación internacional de América Latina..."

Es importante destacar algunas de las ideas expuestas. Los esquemas de integración de América Latina han tendido normalmente a consagrar, mediante un programa de liberación, sea automático - negociado, preferencias regionales no "selectivas". Mientras mayor fuese el número de concesiones, mejor. El denominado "patrimonio histórico" de la ALALC es una muestra clara de ello. Las concesiones incorporadas en las listas respectivas alcanzaron a 15.000. Las "retenidas" en posteriores "acuerdos de alcance parcial" celebrados al amparo de la Asociación Latinoamericana de Integración (ALADI) y que fueron consideradas de interés, disminuyó sensiblemente el número inicial. Suponemos que el criterio de "selectividad" que se expresa, debe manifestarse en negociar concesiones que sean capaces, efectivamente, de generar corrientes de comercio y debidamente amparadas por instrumentos jurídicos comunes que las hagan ciertas y estables.

La "revalorización del mercado latinoamericano" podría, al menos, empezar a producirse, por el otorgamiento de un "margen de preferencia zonal" de alcances generales y que sólo variara según èl grado de desarrollo económico del país que lo otorgue. La triple categoría de países creada en ALALC y profundizada en ALADI parece ser un hecho insoslayable.

El objetivo del logro de una mayor capacitación regional en el procesamiento de recursos naturales, especialmente en el sector agropecuario, nos parece fundamental. En este sentido, los últimos esfuerzos del Pacto Andino, aunque circunscritos a un número reducido de productos agrícolas. son de gran importancia. No vemos razones para que no se contemplen mecanismos similares en los acuerdos agropecuarios a que se refiere ALADI y que, hasta la fecha no han tenido ninguna expresión concreta.

Los acuerdos de complementación económica en algunos sectores específicos deben tender, como señala Tomassini, al aumento de 
la eficiencia y la competitividad y no estar amparados por una protección arancelaria permanente o excesiva. Si en ALALC fueron concebidos como simples instrumentos auxiliares a la desgravación arancelaria general proyectada, en el Acuerdo de Cartagena. al menos inicialmente, se les pretendió someter a una disciplina demasiado rígida que actuó como elemento disuasivo.

En términos generales, el proceso debe orientarse a crear un "área de preferencias económicas múltiples"; facilitando la circulación del capital regional para constituir empresas mixtas; procurando un abastecimiento regional prioritario; utilizando selectivamente el poder de compra de los organismos públicos; normando la competencia comercial en términos leales y equitativos; promoviendo una seguridad alimentaria regional.

De preferencia, debieran utilizarse acuerdos que comprendieran a todos los países de la región y determinar, en caso contrario, unas modalidades muy claras de "multilateralización" obligatoria posterior. En lo que concierne a la dimensión externa del proceso, ésta también debe ser "selectiva". No han sido particularmente aleccionadoras algunas experiencias retóricas recientes. La proyección externa, al menos inicialmente, debiera reflejar un apoyo solidario a necesidades internas muy específicas y puntuales, especialmente tecnológicas y financieras. El tratamiento del Sistema Económico Latinoamericano (SELA) como instrumento viable para estos propósitos está prácticamente ausente de la obra en comentario.

Aparte de estas consideraciones generales que complementan la visión de los objetivos expuestos con la posibilidad de utilizar algunos instrumentos precisos, parece útil referirse, brevemente, al análisis de ciertos "casos nacionales" que se exponen en la Segunda Parte de la obra en comentario y que, a nuestro juicio, le dan originalidad y franqueza al tratamiento del tema de la integración regional que es el que específicamente nos interesa.

Patricio Chaparro, en el Capitulo 6, trata: "El desarrollo político del Brasil, su política exterior y la integración de América Latina".

Ghaparro, sin los eufemismos habituales de los analistas políticos, dice, pura y simplemente la verdad al afirmar: "El Brasil ha demos" trado tener muy poco interés por los acuerdos multilaterales integracionistas, incluso del tipo limitado a objetivos puramente económicos, como Alalc. Menos interés aún ha demostrado por aquellos procesos de integración que incluyan otras dimensiones que las económicas -tales como variables políticas culturales- del tipo Pačto Andino".

Simplemente para complementar la afirmación de Chaparro cabrían algunas consideraciones. Una vez dentro de ALALC jamás quiso Brasil apartarse de lo que no fuera, lisa y llanamente, el perfeccio- 
namiento de una zona de libre comercio y de unos acuerdos de complementación estrictamente "mercantilistas".

Los mecanismos inicialmente previstos por el Tratado, integramente insertos en la desgravación arancelaria, fueron bien aprovechados por Brasil. En términos relativos, el proceso le resultaba conveniente y lo hacía sentirse partícipe (con ventajas y sin esfuerzo) de la comunidad regional.

Durante la vigencia de ALALG (esto es, hasta 1979) Brasil había otorgado menos concesiones que Argentina en su Lista Nacional y participado activamente en acuerdos de complementación reducidos a un escaso número de productos y sin instrumentos propios de un proceso de "integración" sectorial. Las exportaciones e importacio nes de Brasil al área le representaron alrededor de un $12 \%$ del total de su comercio exterior y significaron un $25 \%$ del comercio intrarregional (porcentajes aproximados).

Tengamos presente que Brasil representa más del $40 \%$ de la extensión territorial, de la población, del producto bruto interno de los países de ALALG (hoy, ALADI).

Los esfuerzos desplegados por algunos países para introducir dentro de ALALC (y posteriormente en ALADI) algunos elementos, estimados importantes para "reorientar" el proceso sobre bases más dinámicas o equitativas, no encontraron respaldo por parte del Brasil, como tampoco su oposición directa tajante. Me refiero a la creación de una Comisión Técnica que actuara como un órgano "comunitario" dotada de facultades de "proposición"; a los proyectos para reconocer "tres categorías de países", dotadas de un estatuto jurídico discriminatorio según el grado de desarrollo económico y a la más ambiciosa tentativa de introducir un marco coordinador de políticas en el esquema (Resolución 100). Estos elementos terminaron por introducirse en forma "desvirtuada" e inofensiva.

Posteriormente, la actitud de Brasil frente a sELA, fue de franco recelo. Está claro, además, que a Brasil no le interesan, como instrumento genérico, las agrupaciones subregionales dentro del esquema. Probablemente si aprobó el nacimiento del Pacto Andino en el marco de Alalc fue porque nunca creyó demasiado en su perfeccionamiento. Sólo en muy raras ocasiones. Brasil ha traspasado las barreras del escepticismo en lo que concierne a las estructuras regionales.

Cabría analizar la actitud que adoptaría Brasil ante unos entendimientos muy precisos entre Argentina y el Grupo Andino.

Más adelante afirma Patricio Chaparro que: "sin embargo, existe una ciẹrta integración que interesa a Brasil, que es aquella de intención geopolítica, en un área geográficamente específica: la Amazonia. El Brasil está interesado en controlar política y militarmente esa zona $y$ es por ello que ha contribuido de manera activa y entu- 
siasta en la creación del Pacto Amazónico". Concordamos con Chaparro en el interés brasileño en esa región. Pero vemos difícil la estrategia. Nadie puede dejar de tener presente el inmenso potencial de la región amazónica y la preponderancia brasileña en el área. Los peruanos y venezolanos son particularmente perceptivos sobre esa situación y, salvo circunstancias muy extraordinarias, Brasil habrá de demostrar gran cautela en afirmar sus intereses en esa zona desde la cual puede iniciar, sólo desterrando difíciles suspicacias, una convergencia con el Grupo Andino. Basta estudiar la evolución sufrida por el Pacto a través de su negociación, para atisbar el nivel de intenciones "supuestas" que hubo de vencer; al punto que la propuesta brasileña inicial resulta irreconocible en el Tratado de julio de 1978.

Dijimos anteriormente que a Brasil no le interesaban, como instrumento genérico, los acuerdos subregionales dentro del área. Formulamos la apreciación de esa manera, por cuanto la propuesta original de Brasil en relación a la "cooperación amazónica", contenía la fórmula de una "unión aduanera" entre aquellos países.

Hay otra afirmación de Patricio Chaparro que merece comentario. El autor afirma que: "para los objetivos políticos y geopolíticos del Brasil, la integración es percibida más bien como un proceso que favorece o puede favorecer a su tradicional adversario, la Argentina. Es por esto que el Brasil tiende a practicar una política internacional desfavorable a la integración o bien de apoyo selectivo a aquellos procesos integracionistas en que el Brasil tiene claros intereses políticos, geopolíticos o económicos".

Lo que resulta paradojal es que Argentina no ha demostrado una vocación integracionista clara y dentro del marco de ALALG y en la discusión del Tratado de Montevideo 1980, mantuvo, básicamente una actitud muy cercana a la del Brasil. La afirmación de Chaparro que pudo ser válida hasta mediados de la década de los 60 se diluye "progresivamente" a partir de esa fecha.

Los esfuerzos más sintomáticos de Brasil, dentro de América Latina, estos últimos años los ha emprendido, precisamente, para intensificar sus vínculos con Argentina. ¿Será posible suponer que lo ha hecho sólo para "neutralizarla" frente a posibles entendimientos con otros países o grupos de países en el área? ¿O ha actuado, en buena medida, a requerimiento de la propia Argentina? Parece ser que Brasil ha aprovechado, una vez más, unas circunstancias favorables en que se dan ambos supuestos sin haberse molestado en absoluto en provocarlos.

Analistas brasileños y argentinos de las relaciones recíprocas entre sus países, suponen superadas las etapas anteriores basadas en la hipótesis del "conflicto permanente", aủn cuando no se haya pasado 
en los hechos a articular un sistema eficaz de cooperación económica y tecnológica entre ambos países.

El cambio ocurrido en las relaciones entre Brasil y Argentina es un hecho fundamental del nuevo panorama latinoamericano, ratificado recientemente por los sucesos de Las Malvinas que le dificultan notablemente a Estados Unidos la búsqueda de socios "privilegiados" en el área.

Estos últimos meses, Brasil ha demostrado un interés manifiesto en participar activamente en instituciones regionales expresivas de la integración energética, como es el caso de olADE y del programa de cooperación vigente en ese sector. En ese aspecto, se abren amplias posibilidades de cooperación con Brasil.

En síntesis, podríamos decir que el éxito que ha tenido Brasil en los esquemas de integración y cooperación regional, es el de hacer creer a otros países del área que "la única política pragmática y realista", es la suya. Lo cual es cierto para los intereses brasileños que tienen una "dimensión" muy atípica en la región. Ese es un éxito político y diplomático de gran alcance; hacer del pragmatismo brasileño una doctrina de alcance general.

No podríamos dejar de referimos al logro obtenido por Brasil en las negociaciones del Tratado de Montevideo 1980 al hacer aprobar el artículo 27 de dicho instrumento legal en cuya virtud se pueden concertar acuerdos de alcance parcial con países en desarroIlo no latinoamericanos sin que se extiendan esas ventajas a la ALADr.

Probablemente el único país de ALADI con intereses inmediatos para materializar esa importante excepción a la cláusula de la nación más favorecida sea Brasil, que ha manifestado un creciente interés por vincularse a países africanos, es un espectro lleno de posibilidades.

Por su parte, Alberto van Klaveren, en el Capítulo 7 analiza el caso de México. Tal como señala el autor, ese país: "se ha convertido gradualmente en uno de los miembros latinoamericanos más importantes del sistema internacional. Tanto el análisis tradicional de sus elementos de poder como un recuento de la actividad externa desplegada desde y hacia México comprueban este aserto. Para empezar con el enfoque más tradicional, basta recordar que en términos de tamaño, emplazamiento geográfico, población, recursos naturales comprobados, niveles de industrialización, diversificación de su estructura económica, estabilidad y continuidad políticas, desarrollo educacional y cultural, nivel de institucionalización de la administración pública, y, en menor medida, grado de integración nacional, México se ha convertido, junto al Brasil, en uno de los dos países más importantes de la región latinoamericana. Como una proyección natural de esta tendencia, que se ha visto reforzada por el renovado status de México como una de las mayores potencias 
petroleras del mundo, la actividad internacional desplegada en torno al país es, al menos en términos regionales, notable".

Uno de los hechos positivos de ALALG, es el haber permitido que México se integre progresivamente al comercio de sus países miembros, habiendo más que duplicado sus exportaciones al área y cuadruplicado sus importaciones durante la vigencia del Tratado de Montevideo 1960. Con todo, las importaciones mexicanas apenas representan un $6 \%$ de las que efectúa en los Estados Unidos. EI año 1981 México vendió en ALALC 272.644 y compró 586.494 miIlones de dólares. Las mismas operaciones" con Estados Unidos fueron de 5.878.956 y 9.511.306, respectivamente.

Las exportaciones de México al Mercado Común Centroamericano en 1981 fueron casi idénticas a las que efectuó a los países de ALADI con la diferencia que mantiene frente a Centroamérica un superávit comercial superior a los 200.000 dólares y en relación a ALADI, un déficit superior a los 300.000 dólares.

Durante las discusiones que se mantuvieron para determinar la suerte de las concesiones vigentes en ALALG vencido el período de perfeccionamiento de la zona de libre comercio, a partir de marzo de 1980, México sostuvo la necesidad de preservar el denominado "patrimonio histórico" de ALALC e insistió en mantener el carácter "multilateral" del esquema, vigilando, en la mayor medida posible, que las acciones parciales (en que no participan todos los paises) tendieron a ese fin elemental.

Obviamente, México no va a emprender con los países del Cono Sur ni del Grupo Andino, iniciativas que le entraben su presencia protagónica en 'Centroamérica. México obtuvo la aprobación dei artículo $2 \breve{5}$ del Tratado de Montevideo 1.980 que permite otorgar a otros países del área o a esquemas latinoamericanos de integración económica concesiones aún mayores que las pactadas en ALADI realizándose al efecto las "consultas" del caso. Salvo lo relativo al comercio exterior mexicano, no se encuentran estudios actualizados sobre la inversión de dicho país en Centroamérica $u$ otros antecedentes que revelen la realidad de su presencia en el istmo. Esta variable del panorama mexicano, como su tradicional dependencia de los Estados Unidos son desarrolladas por Van Klaveren con amplitud suficiente. Conviene aclarar que México no ha insistido recientementẹ, en la fusión de los esquemas de integración como lo hiciera con anterioridad en dos oportunidades.

El autor destaca, contraponiéndolas, dos posibles actitudes mexicanas frente al proceso de integración (cita al efecto un trabajo de König) ; la: "comercialistạ-exportadora" y la "desarrollista-integracionista". Con razón, afirma que, al menos dentro de ALALG la posición comércialista prevaleció claramente. Al finalizar dicho esquema por voluntad de las partes, más que por consideraciones jurí- 
dicas, México mantuvo una posición más ortodoxa (más leal a los mecanismos iniciales de ALAIC) que Brasil y, por cierto, que Argentina en defensa de la multilateralidad básica propia del Tratado.

El papel relevante de México en la aprobación del Convenio de Panamá que dio origen al SELA y que menciona Van Klaveren, se ha manifestado, posteriormente, en una activa participación de ese país en el organismo. Integra, al igual que Perú y Venezuela, todos los Comités de Acción que allí funcionan. Han transcurrido siete años de vigencia del sela y se han sucedido tres gobiernos en México.

Uno de los logros más importantes de los organismos de integración y cooperación regional, es haber consolidado la presencia de México en el área en términos tales que en la actualidad resultaría inconcebible políticamente emprender acciones de alcance global sin su participación. Por otra parte, tanto el sector empresarial mexicano, como el sector público, más compenetrado de la realidad industrial de su país que sus equivalentes en otros estados de la región, han adquirido conocimiento y conciencia de la variable "latinoamericana" en el destino mexicano.

En febrero de 1979 el entonces secretario de Estado, Cyrus Vance, señaló la posibilidad de crear "un mercado común entre México, Canadá y Estados Unidos". A su vez, el programa político del Partido Republicano contempla la idea de "fomentar una cooperación más estrecha y el beneficio mutuo entre Estados Unidos, Canadá y México". Al respecto señala que: "... Ios republicanos reconocemos la importancia fundamental de México, el restablecimiento de buenas relaciones con este país debe tener una alta prioridad. ... reconociendo que cada país tiene contribuciones únicas que hacer en la resolución de problemas prácticos".

'Con todo, Ia opinión mexicana sobre el particular, afortunadamente, parece ser la que expresa con propiedad Claudio F. Urencio, al señalar que "ese mercado común (èl propuesto por Vance) implicaría acelerar el proceso de dependencia de México respecto de Estados Unidos, por la gran asimetría de ambas economías; además, México se alejaría necesariamente del proceso de integración de América Latina y de las posiciones políticas de los países deI Tercer Mundo". Más aún, Urencio señala categóricamente que: "una vez ampliada la frontera económica y afianzada la solidaridad política entre arabos países, México se integraría a la economía, a la cultura $y$ al destino de Estados Unidos, desintegrando la identidad nacional del país"’.

Esforzándonos por hacer un paralelo entre la política regional de Brasil y México, podríamos concluir que para el primero resulta imprescindible "estar presente" en los organismos de cooperación.

${ }^{1}$ Comercio Exterior. Banco Nacional de Comercio Exterior S. A. Vol. 31, número 10. México, octubre de 1981, p. 1184. 
e integración regional, sin adquirir compromisos que, "dentro de la región", impliquen adquirir obligaciones que le recuerden su categoría de "mayor desarrollo económico relativo" y que "fuera de la región" le coarten su libertad de acción comercial. Para México, es útil contar con instrumentos comerciales regionales, sólidos y estables, que aminoren su dependencia de los Estados Unidos y.le faciliten a la vez, su papel de "puente" entre Sud y Centroamérica. Obviamente, le interesa, más que a ningún otro país del área, la "proyección externa" de la región para mejorar su capacidad de diálogo con el vecino. Mientras Brasil debe vencer las "suspicacias" que despierta su "dimensión" en el área, México debe tratar de no provocarlas más allá de lo tolerable al norte de sus fronteras, al menos mientras exporte a Estados Unidos casi el $50 \%$ de sus ventas totales y compre allá el $65 \%$ de sus importaciones.

En cierto sentido Venezuela, cuyo caso es tratado por Carlos Portales, presenta rasgos similares a los de México en su vertebración al área. Al menos en tres aspectos, los cuales son mencionados adecuadamente por Portales, es posible formular el símil:

a) Su fuerte dependencia de los Estados Unidos de América y su escasa vinculación comercial con el área. Durante la vigencia de ALALC sus exportaciones a la región apenas representaron el $4 \%$ de sus ventas totales. Las importaciones intrarregionales no alcanzan al 7\% de las importaciones globales;

b) Su posibilidad de enhebrar vínculos especiales con otras subregiones del área. En este caso, con los países del Caribe;

c) Su "conciencia integracionista" expresada felizmente por Portales al señalar que: "el proceso de discusión amplia del tema de la integración dentro de la arena política venezolana perimitió el desarrollo de una verdadera ideología integracionista que se incor poró a las formulaciones de política exterior del país. Esta ideología ha coadyuvado a la mantención de las políticas de integración a través de los distintos gobiernos de Acción Democrática y coper".

La discusión de todos los mecanismos elegidos por los países para llevar a cabo el proceso integracionista ha sido bastante intensa en Venezuela. La "legitimidad" como requisito fundamental de un proceso que puede comprometer a toda la comunidad nacional organizada, parece lograda plenamente en el caso venezolano, tanto en el ámbito empresarial como sindical aparte de los partidos políticos que señala Portales.

Pasado el régimen de Pérez, como el de Echeverría, en México, el país ha mantenido básicamente su fidelidad a la causa latinoamericana; tanto en el Grupo Andino, como en SELA. Es bastante escasa, eso sí, la importancia otorgada por Venezuela a ALADI, aun cuando manifiesta, esporádicamente, interés por vincularse en forma más estrecha a Argentina y a Brasil; en el sector energético. 
De más está destacar la relevancia venezolana en el marco del Acuerdo de Cartagena. Representa el 20\% del territorio y de la población subregional; más del $40 \%$ del producto bruto y más del $50 \%$ de sus reservas internacionales.

Es ya tradicional el papel protagónico de Venezuela en el seno de la Corporación Andina de Fomento $y$ en el Fondo Andino de reservas.

Se prevé que el año 2.000 habrá en el Caribe 20 o más entidades políticas, todas nominalmente independientes, excepto las Antilläs Francesas y Puerto Rico. La población total se aproximará a los 40 millones. Esta nueva circunstancia será determinante en la política exterior de Venezuela y en todo el cuadro político regional.

"El Sistema Político Peruano y la Integración" es el Capítulo 10 de la obra a cargo del profesor Manfred Wilhelmy.

Según el autor "Ia participación y el apoyo peruano a los acuerdos de integración no pueden ser entendidos en términos puramente comerciales". Ello es tan efectivo que sólo por razones doctrinarias se entiende el fervor demostrado por Perú en aprobar la Decisión No 24 concerniente al tratamiento común al capital extranjero. Asimismo, Perú ha sido claro en manifestar la necesidad de que el proceso se proyecte a otras áreas distintas a la económica, como es el caso del Convenio Andrés Bello (de integración científica y cultural), Simón Rodríguez (de integración laboral) e Hipólito Unanue (de salud pública).

Como se desprende del análisis de Wilhelmy, no sólo parece haber diferencias retóricas entre los planteamientos sucesivos de Velasco, Morales y Belaúnde acerca de la visión peruana de "los instrumentos" propios del proceso. El énfasis puesto inicialmente en el nacionalismo económico y consecuencialmente, en el proteccionismo arancelario se ha ido, indiscutiblemente, diluyendo. No ha estado ausente del panorama económico peruano el Fondo Monetario Internacional y sus recetas ortodoxas. En todo caso, las diferencias de los sucesivos gobiernos peruanos no han implicado una pérdida de la fidelidad integracionista. Lisa y llanamente ha ocurrido un evidente deterioro del proceso frente a lo cual Perú no ha reaccionado con mayor interés. Es más, ha contribuido involuntariamente al hecho.

Casi matemáticamente las alternancias en el poder se han reflejado en las posiciones peruanas frente al arancel externo común, cuya no aprobación mantiene en difícil situación al esquema impidiendo proyectarse como una unión aduanera. No han sido escasas las trabas impuestas por Perú al intercambio subregional. Por otra parte, ignoramos la real aplicación en Perú de las principales obligaciones emanadas del Régimen Común al Capital Extranjero, como para emitir un pronunciamiento del estado actual de lo que se llamó ayer "doctrina Velasco" sobre la materia. No parece haber 
variado hasta la fecha el panorama que presenta Wilhelmy. En tode caso, en comparación con Brasil, México o Venezuela, Perú (como 'Chile, Colombia y Uruguay) resultan países "inescapablemente" insertos en la región.

Más aún, Perú con Ecuador y Bolivia presentan una fuerte identidad cultural y sociológica, más nítida en todo caso que otras que se puedan proyectar en otras subregiones del área.

Todas las instituciones que forman el denominado "Sistema de Integración Andina", cualesquiera sean los juicios que merezcan (incluyendo el Consejo Andino, el Parlamento Andino, el Tribunal de Justicia), se supone que revelan una ambiciosa búsqueda de convivencia vertebrada y armónica en la subregión y fueron puestas a prueba duramente por el "conflicto peruano-ecuatoriano", mostrando un alto nivel retórico. Lamentablemente. Sin duda alguna el bien jurídico implícitamente protegido de mayor jerarquía en toda organización regional es la paz entre sus miembros. Principio y fin del sistema.

Para poner término a estas ya largas reflexiones sólo nos cabe felicitar a los autores y al Centro editor de la obra en comentario. 